\title{
Dominante cultural y productos televisivos: géneros que homogeinizan preferencias ${ }^{1}$
}

\author{
Dra. Paulina Beatriz Emanuelli \\ Docente investigadora. Escuela de Ciencias de la Información \\ Facultad de Derecho y Ciencias Sociales. Universidad Nacional de Córdoba \\ Rep. Argentina
}

RESUMEN:

En esta presentación se relacionan características de la sociedad actual, valores imperantes en nuestra cultura y propuestas televisivas.

Primeramente se rastrea la irrupción de la juventud en la pantalla, luego el consumo y preferencias televisivas de jóvenes, se relacionan con estudios anteriores y por último se formulan interrogantes y posibles respuestas.

Tres ideas ejes atraviesan la presentación:

- Hay programas y géneros televisivos consumidos por importantes segmentos de públicos que homogeneizan preferencias que antes estaban diferenciadas por sexo y edad.

- Estos programas y géneros televisivos se corresponden con los principales valores de la mentalidad posmoderna.

- Estos programas y géneros son parte principal en la programación de la TV por cable. Esta industria massmediática, en pleno período de expansión, es la máxima representante del modelo neoliberal globalizante.

ABSTRACT:

The report deals with some aspects of actual society, predominant values and norms in our culture, and television proposal.

Let's us begin with how the young people irrupt into the television screen, then their television use and choose, and finally we propose some ask and answer about these questions.

This report contains three main ideas.

- Some programs and television genres are choused by an important number of television audience segments. These programs changed preferences that in the past was different between sex and age. mentality.

- These programs and genres are agree with the most important values in the postmodern

- These programs and genres take one of the principal places in the programmed cable television. The point is that de cable TV is growing in our region.

Palabras claves: Programas televisivos/Jóvenes/Homogeinizació/Preferencia/Posmodernidad.

Key Words: Television program/Young people/Homogenizing/Preferences/Postmodern.

1 Esta presentación forma parte de uno de los hallazgos del trabajo de tesis doctoral presentado por la autora en la Universidad de La Laguna titulada Estudios de Caso de recepción televisiva de adolescentes de distintos sectores sociales en la ciudad de Córdoba, Argentina, 1998. 


\section{Introducción}

$\mathrm{E}$ n este trabajo se relacionan características de la sociedad actual, valores imperantes en nuestra cultura y propuestas televisivas.

Se rastrea la irrupción de la juventud en la pantalla, el consumo y preferencias televisivas de jóvenes y se relacionan con estudios anteriores formulando algunos interrogantes y posibles respuestas.

Tres ideas ejes atraviesan esta presentación:

a) Que hay algunos programas y géneros televisivos que son preferidos por importantes segmentos de públicos, homogeneizando preferencias que antes estaban muy diferenciadas por sexo y edad.

b) Que estos programas y géneros televisivos se corresponden con la mentalidad posmoderna.

c) Que estos programas y géneros son parte principal en la programación de la TV por cable, industria massmediática cuya evolución la transforma en óptima representante del modelo neoliberal globalizante.

\section{Sociedad contemporánea}

La sociedad actual, producto de profundos cambios económicos que han traído aparejados importantes transformaciones culturales, es abordada y hasta denominada de diferentes maneras.

Stuart Hall designa esta época como 'postfordista', considerándola un estadio posterior del capitalismo. El mismo autor considera esta etapa como resultado de una profunda transformación en los modos de trabajo (tecnología de por medio), en los productos y esencialmente en su comercialización y consumo.

Según D. Bell: «... La ética protestante fue socavada no por el modernismo sino por el mismo capitalismo. El mayor instrumento de destrucción de la ética protestante fue la invención del crédito. Antes para comprar había que ahorrar. Pero con una tarjeta de crédito los deseos pueden satisfacerse de inmediato...» $(1990: 31)^{2}$.

El marco económico de esta sociedad esta caracterizado por el predominio de empresas multinacionales y la globalización de los mercados financieros. En nuestras sociedades, con las agrupaciones obreras y profesionales debilitadas, las multinacionales han actuado con gran autonomía frente a estados débiles que priorizan el ingreso de capitales privados por sobre el bienestar social.

Para Hall la sociedad contemporánea está atravesada por

«...la existencia de una gran fragmentación y pluralismo social, el debilitamiento de viejas solidaridades colectivas y de las identidades concebidas como

2 Lipovestsky, Gilles; La era del vacío. Ensayos sobre el individualismo contemporáneo, Ed. Anagrama, Barcelona, 1996 
'bloques' ante la emergencia de nuevas identidades. Por eso la maximización de elecciones individuales a través del consumo personal son dimensiones igualmente significantes de las tendencias del posfordismo...» (Hall1993:94) ${ }^{3}$. En los medios masivos, especialmente en la televisión, es donde se vislumbra con mayor claridad esta situación como veremos mas adelante.

Frente a esta posición fuertemente económica existen otros autores como Scott Lash para quienes el posmodernismo está confinado al ámbito de la cultura.

«...El posmodernismo es estrictamente cultural. Es sin duda una especie de paradigma cultural... un 'régimen de significación'...» (Lash, 1997:20)

Para Gilles Lipovetsky", la cultura posmoderna mediante un 'proceso de personalización' con marcado sesgo narcisista y hedonista que acentúa el individualismo hasta el egoísmo. Para él, la consigna del sujeto posmoderno es mantenerse joven y hermoso. Se encumbra el placer y el cuerpo. Ya no se habla de dietas, gimnasias o tratamientos médicos para sentirse físicamente bien, sino para lucir un 'envase' o 'envoltorio' atractivo y lo mas joven posible.

Este estilo de vida consumista y hedonista se difunde, con el aporte de la tecnología y los nuevos diseños. La 'estética' ha penetrado el mundo de la producción moderna acorde a los 'nuevos tiempos'.

La 'imagen' se ha vuelto un lugar clave en la comercialización y el consumo. El estilo y su representación del cuerpo son puntos clave donde se apoya el consumo de hoy.

Mas aún, a través de la publicidad, existe una proliferación de mundos que tienen sus propios 'códigos de comportamiento' que remiten a ciertas 'escenas', 'economías' y 'placeres' que sólo pueden ser alcanzados, como en un espejismo, a través del consumo. La sociedad posmoderna va mas allá del consumo, sencillamente lo honra y exalta.

\section{Sociedad 'cool'}

Otro de los rasgos centrales de la mentalidad actual es el planteo del humor y lo cómico.

En el ámbito de lo cotidiano, no se presenta como sarcástico sino mas bien en una dimensión lúdica, relacionada con la seducción y la proximidad de los individuos.

La gente busca la proximidad a través del tuteo y con bocadillos sin pretensión de risas logra 'romper el hielo' es decir, aproximarse. El código de comunicación con el otro se establece en clave de proximidad gestual y verbal humorística.

3 Stuart Hall (1993): 'Nuevos tiempos' en la Mirada oblicua. Estudios Culturales y Democracia. Delfino, Silvia. Ed. La Marca, Buenos aires.

4 Bell, Daniel; Las contradicciones culturales del capitalismo. México.Grijalbo. 1990. 
Hoy, todo es divertido, y debe ser así, en un registro cálido y cordial: un humor cool, que requiere de espontaneidad, naturalidad y se muestra insustancial a la vez que describe un universo radiante.

El humor se incorpora a la seducción junto a otros valores posmodernos como el hedonismo y la banalización en personajes de los medios masivos como: héroes, melodramáticos o personajes burlescos. En los medios masivos, las películas de James Bond, de Indiana Jones y tantas otras de acción norteamericanas así como de otros países ponen en evidencia las características de los nuevos héroes. El personaje en cuestión desdramatiza lo real y se caracteriza por una actitud absolutamente relajada ante los acontecimientos más tensionantes de peligro y violencia. La adversidad es atenuada con el humor tranquilo $(\mathrm{cool})$ y resuelto del héroe que escapa a un fantasmagórico mundo agresivo y de alto riesgo.

En la fiesta posmoderna hay un retorno al uso del disfraz, un cierto retorno relajado de lo carnavalesco, pero en este caso no es una recuperación de la tradición, bien por el contrario, el uso del disfraz marca la búsqueda de una sobrediferenciación individualista.

Lejos del conflicto, la significación y el rebajamiento de lo sublime, esta vuelta al disfraz, se produce en un marco de la «suavización de las costumbres» en donde las groserías y las blasfemias ya no producen risa.

La ironía y la parodia ocupan un lugar cada vez más importante en los medios masivos 5 .

Paradójicamente con la sociedad humorística empieza una liquidación de la risa. Se empieza a disolver progresivamente la propensión de reír. Al respecto Lipovetksy dice:

«...la personalización posmoderna cierra al individuo sobre sí mismo, hace desertar no sólo la vida pública sino finalmente la esfera privada, abandonada como está a los trastornos proliferantes de la depresión y de las neurosis narcisistas; el proceso de personalización tiene por término el individuo zombiesco, ya cool y apático, ya vacío del sentimiento de existir...» $(1996: 146)^{6}$.

Del mismo modo que hay una disminución en los afectos se da una mengua en la facultad de reír. 'Una cierta sonrisa' más cercana a la mueca permanente, sustituye la risa incontenible.

\section{Valores posmodernos}

En este marco civilizatorio, concebida como valor incalculable por la propia sociedad, la juventud se ha convertido en un territorio en el que todos quieren vivir

5 Véanse ejemplos en Cine 'Austin Power' y en Tv programas como 'CQC' de producción argentina, o 'Saturdey night live' en Sony, entre otros.

6 Lipovestsky, Gilles (1996); La era del vacío. Ensayos sobre el individualismo contemporáneo, Ed. Anagrama, Barcelona. 
y gozar indefinidamente. Al decir de Beatriz Sarlo «... la juventud no es una edad sino una estética en la vida cotidiana...» $(1994: 38)^{7}$ a lo que se debe agregar, atravesada por los valores hegemónicos de la mentalidad de esta época.

Aquí, la producción estética posmoderna, a diferencia del modernismo artístico no escandaliza a nadie, por el contrario se encuentra incorporada a la cultura oficial de la sociedad occidental en la medida en que, como dice F. Jameson, se ha integrado a la producción de mercancías en general.

La multiplicación de imágenes sigue la lógica de la producción en general, las imágenes tienen una vida efímera: están destinadas a perdurar, a provocar un impacto y orientar una conducta. Este impacto puede adquirir distintas características relacionadas con el sentimentalismo y la dramatización.

Daniel Bell dice al respecto:

«...Los medios visuales - por los que entiendo aquí el cine y la televisiónimponen su ritmo al espectador y, al destacar las imágenes y no las palabras, no invitan a la conceptualización sino a la dramatización. En el énfasis que las noticias de la televisión ponen los desastres y las tragedias humanas, no instan a la purificación o a la comprensión, sino al sentimentalismo y la piedad, emociones que se agotan rápidamente, y crean un seudorritual de seudoparticipación en los sucesos. Y como la modalidad es inevitablemente de superdramatización, las respuestas pronto se hacen altisonantes o aburridas...»(1993:42 $)^{8}$

Sobre los efectos de este sentimentalismo mediático propuesto a través de las imágenes G.Lipovetsky relaciona a los medios con cierto potencial moralizante sobre los individuos. Al respecto dice:

«...El proceso de erosión de los deberes continúa: mientras los medios apelan periódicamente a los corazones, desculpabilizan las conciencias y trabajan, tal vez subterráneamente, para apartar a los individuos de las obligaciones permanentes de ayuda y beneficencia. El altruismo del posdeber se complace en la distancia: nos hemos vuelto más sensibles a la miseria expuesta en la pequeña pantalla que a la inmediatamente tangible, hay mas conmiseración hacia el semejante distante que hacia nuestro prójimo cercano. La caridad de los medios no culpabiliza, no da lecciones de moral, conmueve mezclando el buen humor y los sollozos contenidos, las variedades y los testimonios íntimos, las hazañas deportivas y los niños impedidos. No ya una moral de la obligación sino una moral sentimental mediática...» (1994:138) .

7 Beatriz sarlo (1994) «Escenas de la vida posmoderna: intelectuales, arte y videocultura en Argentina» Ed. Ariel. Buenos Aires.

8 Bell, Daniel; «El eclipse de la distancia» en La Mirada Oblicua. Estudios Culturales y Democracia; Delfino, Silvia, Ed. La Marca, Buenos Aires, 1993.

9 Lipovetsky, Gilles; El crepúsculo del deber. La ética indolora de los nuevos tiempos democráticos. Ed. Anagrama. Barcelona. 1994. 
Esta erosión de lso 'deberes' se acompaña con la exaltación de modelos y valores que de una forma u otra, son los imperantes en los productos culturales actuales: La seducción, el goce, el placer y el culto al cuerpo están en primer lugar junto a la habilidad para el deporte, la audacia, la fantasía, la diversión en un individualismo exacerbado.

Al decir de Fredric Jameson ${ }^{10}$ en nuestro tiempo, existe una dominante cultural, donde el individuo es el principal protagonista. Las características de esta 'dominante cultural' son:

b) una nueva superficialidad (se relaciona a una nueva cultura de la imagen, estética y simulacro)

c) un tipo nuevo de emocionalidad ('intensidades' basadas en lo individual hedonista y placentero)

d) un consecuente debilitamiento de la historicidad. Tanto en relación con la historia pública como privada. Ya no importa el futuro. Sólo el presente es relevante y algo del pasado que conviva sin conflicto.

e) La profunda relación entre los rasgos antes mencionados, que a su vez constituye la materialización de un sistema económico internacional nuevo.

\section{Lo juvenil en la pantalla argentina}

Es interesante señalar, que la irrupción juvenil en la pantalla argentina, estuvo atravesada por los mismos condicionamientos que marcaron la existencia de la propia televisión y de la sociedad toda: dictaduras militares, vaivenes económicos, legales y desde luego el propio desarrollo tecnológico de la industria televisiva.

Fue a finales de la década de los sesenta cuando se inició la incorporación de la juventud a la TV argentina. Exactamente cuando la industria cultural en general y la televisión en particular tomaron el rumbo definitivo hacia su supremacía.

En un principio la juventud era presentada en postales informativas o reflexivas como resultante de la propia participación que comenzaban a cobrar los jóvenes recordemos el cordobazo en 1969 y las luchas estudiantiles en la década del setenta.

Con el crecimiento de la producción nacional ${ }^{11}$ y las compañías discográficas los programas musicales cobraron importancia. Se realizaron programas como: Club del Clan (Canal 13), Ritmo y juventud (canal 11) entre otros.

10 Frederick Jameson (1992) «El posmodernismo o la lógica del capitalismo avanzado». Ed. Piados. Buenos Aires.

11 En 1968, por ejemplo, la proporción de porgramación nacional en los cuatro canales de la capital federal alcanzaba a un $75 \%$. (Anibal Ford 1987:31) 
Las temáticas juveniles fueron incorporándose a la TV en programas en los que incluso tenían en un rol protagónico. Como ejemplo recordemos el programa 'La Nena' con Marilina Ross y Alberto Miranda serie que luego repuesta en la década del ochenta con el protagónico de Rodolfo Ranni como papá de la nena.

En la época del Proceso Militar y en plena vigencia de las 'Listas negras' la presencia juvenil mas fuerte fue ligada a la sospecha o instigación o bien totalmente integrada al régimen desde una perspectiva nacionalista. El deporte y especialmente del fútbol fueron mas que esenciales en la política televisiva.

Fue en la década del ochenta, con la vuelta a la democracia, en que la temática juvenil se consolidó definitivamente. La mayor libertad y aumentó la participación de los jóvenes en programas de debate que trataban problemas sociales vigentes.

En esta década surgieron algunos géneros que después se consolidarían como 'Semanario Insólito' o' La noticia rebelde' que fueron iniciadores en el periodismo humorístico.

Surgen 'las novelas blancas' o melodramas juveniles como 'Clave de sol' que fue la primera protagonizada casi íntegramente por adolescentes y pre-adolescentes.

A fines de los ochenta, acompañando a la música juvenil, comienza a instalarse la estética del videoclip, donde predominan y se acentúan los montajes rápidos, no lineales y con diversidad de recursos estéticos.

Resumiendo 'lo juvenil' ${ }^{12}$ en la pantalla cobra protagonismo en:

1. lugares de la producción televisiva.

Inicialmente como ayudantes de producción, los jóvenes, poco a poco, fueron escalando posiciones en y ocupando lugares en esta área. Hoy muchos de aquellos son conocidos productores.

\section{Distintos géneros en la programación.}

Por ejemplo en la presentación de noticias, que se había manejado con el reconocimiento a trayectorias periodísticas que acentuaban la credibilidad pública, se pasó a la incorporación de jóvenes estéticamente atrayentes.

En los melodramas o telenovelas tradicionales comenzaron a presentarse personajes y actores que apenas superaban los veinte años.

La proliferación de megarrecitales, verdaderos espacios de construcción de identidades juveniles, ocupó un relevante lugar como acontecimiento periodístico.

3. A nivel de temáticas en distintos programas.

En los programas de interés general o variedades e informativos, se reivindica el tratamiento de los temas con códigos de identificación y reconocimiento

12 Véase 'Vidas Imaginarias. Los jóvenes en la tele'. Gándara, Santiago y otros. Ed. Biblos, 1997. 
juveniles. Sólo que la conducción y el formato televisivo sigue en manos de adultos.

A finales de los ochenta se instala una fuerte presencia juvenil en la TV a través del deporte, la música, la moda y la publicidad.

\section{La ' juvenilización' de la pantalla}

En los noventa, el concepto de adecuación de la televisión a las leyes del mercado y de la acumulación económica produce una fuerte centralización en el ámbito de la producción y distribución de las programaciones.

Con el inicio de la transmisión en satélite y posteriormente con el advenimiento de los canales de cable, en la década de los noventa, se produce en Argentina, la 'juvenilización' de la pantalla. Las temáticas juveniles envueltas en humor, aventura, belleza y sensualidad ganan los espacios televisivos fundamentalmente en los canales por cable.

$\mathrm{Si}$ en un principio, la juventud fue un objeto de importancia relativa, en los noventa 'lo juvenil' llegó a convertirse en privilegiado y central. Se diría que la televisión llevó a cabo un sobredimensionamiento de la juventud, a tal punto que la exalta como un objetivo de vida permanente.

La creación de esta imagen de juventud relacionada con el modelo estadounidense, adquiere con la globalización y la desregularización económica una dimensión «mundial» que tiende a homogeneizar gustos y consumos sociales y culturales. Es en la búsqueda de esta homogeneización en que las ideologías comienzan a diluirse.

Inicialmente se da proceso de 'borramientos de diferencias' para lograr la homogeneización del imaginario juvenil, se dejan de lado, las condicionantes de origen geográfico y regionales y las determinaciones de clase y sector social. Paradójicamente en el mismo momento en que se avanza en la homogeneización se inicia una búsqueda de segmentación y diferenciación en la audiencia televisiva.

Como ocurre en el campo económico, más precisamente en el marketing, donde se produce para un determinado grupo de consumidores y similar a las estrategias de publicidad dirigidas a un target determinado, la programación de la TV se suma al fenómeno de la fragmentación del consumo.

En la sociedad no hay un solo tipo de joven. La televisión en cierta forma aprovecha esa diversidad, no obstante el estereotipo de joven urbano medio que presenta frecuentemente. La TV busca reflejar las desigualdades pero en lugar de centrar las diferencias en la clase social, nivel educativo, lugar de origen, tipo de trabajo, etc.

De esta manera el público de Tinelli («Videomatch») no es el mismo que el de Pergolini («Caiga quien Caiga»), no prefieren la misma música, ni los mismos programas, ni tienen las mismas actividades recreativas, etc. Aunque ambos apelen al humor no es lo mismo el grotesco que la parodia y la ironía. 
De todas maneras, aunque hay distintos tipos de jóvenes, en la Tv por cable, se propone fundamentalmente desde la ficción, una imagen juvenil estereotipada que ese desenvuelve en un ambiente despolitizado, y por fuera de conflictos sociales. Las historias de los jóvenes que se cuentan en la TV, se dan fuera de los espacios del trabajo y la marginación. Sólo se incluyen estos espacios vaciados de conflicto.

Si bien la juventud constituye un momento de incertidumbre ideológica y más bien de certezas con respecto a ideas generales, el imaginario juvenil presentado en televisión se muestra despolitizado de argumentos y personajes. Este modelo se vislumbra con mayor fuerza en la TV por cable en melodramas como 'Dawson's creek' de SONY o programas humorísticos como 'Ally Mac Beal', 'Dharma y Greg' de FOX. Es un modelo muy presente en el cable de hoy.

En general, el discurso televisivo de ficción realiza pocas referencias a partidos políticos, lenguaje sobre conflictos sociales, políticos y casi nunca se muestran personajes de jóvenes que se dediquen a la política. Recién en los últimos años y en la Tv argentina, con la inclusión de las telenovelas 'Gasoleros' y 'Campeones' o programas como 'Verdad o Consecuencia' volvió a la televisión un mundo excluido por décadas.

Sin embargo, con respecto a los programas dirigidos a los mas jóvenes, como 'Cebollitas' o 'Chiquititas', los personajes corresponden básicamente con una clase media acomodada y urbana que coincide con la imagen estética del mundo publicitario y reproducido en la Tv por cable. En otras telenovelas como 'Verano del 98' se recuperan características de los teleteatros y ponen en evidencia una precocidad en el ámbito sexual y sensual que era impensable décadas pasadas.

La «juvenilización» de la pantalla coincide ciertamente con un avance del 'efecto joven' que se relaciona con las formas de trabajo pero se encuentra totalmente imbuido de los valores imperantes y presentes en los procesos sociales y culturales.

De esta manera, en los sesenta y setenta coexistieron los valores orientados a la búsqueda de la paz, libertad, anticonvencionalismo, sensibilidad estética, sentimiento frente a una racionalidad pragmática coincidente con la conciencia del trabajo, sacrificio, ahorro, moral.

Desde fines de los ochenta y en los noventa, retomando a Fredric Jameson, existe una dominante cultural, que se materializa en un sistema económico internacional: el neoliberalismo salvaje. Acordes a esa dominante cultural una nueva superficialidad (se relaciona a una nueva cultura de la imagen, estética y simulacro), un tipo nuevo de emocionalidad ('intensidades' basadas en lo individual hedonista y placentero) y una ausencia de la historicidad, constituye la esencia de los productos y bienes simbólicos circulantes.

En la TV abierta y el cable, la publicidad es quizás donde mejor se exponen y sintetizan los rasgos de la representación juvenil televisiva y los valores impe- 
rantes en esta época. La juventud que muestra la publicidad es básicamente clasista, con un increíble tiempo libre y una total despreocupación social, lo que reafirma su pertenencia a la clase hegemónica. Disfruta de deportes audaces, se deleita en el consumo, y presenta estereotipos estéticos que se han convertido en arquetipos. La juventud en la publicidad constituye un grupo independiente, fuera del trabajo, la familia y el estudio; sin embargo, se representa consumiendo en grupo y en actitudes festivas. En ese caso el producto publicitado suele ser la razón del contacto como ejemplo se puede mencionar el rubro de bebidas y jeans.

En cuanto a los valores presentados: la seducción, el goce, el placer y el culto al cuerpo están en primer lugar.

Luego el deporte, la audacia, la fantasía, el humor, conviven con el desgano, la palidez y un cierto enfrascamiento personalista de «estoy en otro mundo, esto no me llega».

Acorde a los principios posmodernistas se impone la coexistencia flexible de las antinomias. De ahí que convivan una realidad sofisticada y espontánea, renovadora y retro, porno y discreta, todo en coexistencia pacífica pero cuidadosamente elaborado según cuál sea el público meta al que está dirigido.

En este marco, concebida como valor incalculable por la propia sociedad, la juventud se ha convertido en un territorio en el que todos quieren vivir y gozar indefinidamente.

\section{Consumo y preferencias juveniles}

En principio hay que decir que en muy poco tiempo el cable ha tenido una expansión importante. En 1993 sólo el $36 \%{ }^{13}$ de los hogares cordobeses tenía cable, en $1995^{14}$ el $50 \%$ de la población cordobesa tenía cable «...un $50 \%$ de los hogares encuestados cuentan con este tipo de servicio. Del resto, sólo el 19\% manifiesta no tener interés en poseerlo, mientras que un porcentaje similar no puede acceder por razones económicas...» (Mata, 1995: 25).

Con el mejoramiento tecnológico del cable, creció la competencia entre las empresas y en consecuencia se ampliaron sus redes de distribución, mejorado sus servicios y precios, dando lugar a la apertura de nuevos mercados. De esta forma individualmente o con conexiones compartidas, los sectores populares en Córdoba, han accedido a la TV por cable. Desde luego no es igual la adopción del cable por sectores populares en zonas rurales o de escasa población.

13 Según datos publicados en ATVC Revista TV Cable No21 en 1993 citado por Schmucler H y Terrero P. Innovaciones tecnológicas y transformación en la televisión argentina. En Voces y Culturas $\mathrm{n}^{\mathrm{a}} 91^{\mathrm{o}}$ Semestre, Barcelona, España.

14 Según estudio realizado por Mata María Cristina en 1995 ?Públicos y consumos culturales en Córdoba» Proyecto de Investigación. CEA, UNC, Mimeo. 
Esta penetración del cable en la sociedad cordobesa, está acompañada por una transformación en las preferencias de la audiencia juvenil. Hablar de preferencias implica hablar de los programas que priorizamos, elegimos o vemos con mas placer que otros. No significa el consumo total de televisión.

Diez años atrás, cuando el cable tenía poca penetración en Córdoba, las preferencias de programas televisivos según el sexo, se mantenía bien marcada, sin importar la edad de los jóvenes. Las preferencias femeninas se orientaban hacia las telenovelas y los varones se orientaban hacia deporte y descalificaban en forma contundente la telenovela. ${ }^{15}$

En el estudio realizado recientemente se puede afirmar que:

1) con respecto a las preferencias de programas por sexo, se puede decir que a menor edad hay mayor diferencias entre las preferencias de varones y mujeres. Las mujeres se inclinan visiblemente hacia los melodramas y los varones hacia el deporte.

2) con respecto a las preferencias por edad: A medida que aumenta la edad se van achicando las diferencias entre programas preferidos y se distinguen programas y hasta géneros que comparten. Entre ellos el humor presente en 'La niñera' que fue elegido por todos los segmentos ${ }^{16}$ etarios, 'Los Simpsons' y también programas humorísticos como Video Match en los sectores populares y C.Q.C. en los sectores medio altos. Aunque muchos de los varones mayores no marcaron como preferido a 'Verano del 98' conocían los personajes y las historias, a modo de excusa, algunos plantearon que era porque hacían zapping o porque los veían sus hermanas. Del mismo modo, jóvenes entrevistadas mayores plantearon la preferencia por acontecimientos 'deportivos importantes' como por ejemplo ver el mundial de fútbol cuando juega Argentina.

Resumiendo, las convergencia en las preferencias están dadas entonces en:

1. programas de humor ('la niñera' ( The Nanny), los Simpsoms, etc.)

2. melodramas ligeros (como 'verano del 98')

3. programas deportivos en general

¿Cómo explicar esta homogeinización en los gustos televisivos de los jóvenes? ¿Porqué a mayor edad de los jóvenes se manifiesta una mayor coincidencia en las preferencias?

En principio se pone en evidencia que el humor, el melodrama y los deportes son los nexos de convergencia. Queda en evidencia además que justa-

15 Según estudio realizado por Emanuelli y otros en «Recepción juvenil de la TV en Córdoba» Informe final subsidio CONICOR 1990. Córdoba. Mimeo.

16 Cabe destacar que al momento de la recolección de datos, la Niñera se emitía por TV abierta y Por cable capítulos estrenos en SONY. 
mente en estos programas, como en la publicidad, es donde más se exhiben los valores de la época. Seducción, goce, placer y culto al cuerpo están en presentes en el melodrama. La necesidad de diversión y no preocuparse de pasarla 'cool' está presente en el humor y el deporte. La audacia, fantasía y rebeldía, junto a la ironía y la burla ayudan a olvidarse del pasado y futuro invitando a disfrutar el presente están presentes en numeroso programas humorísticos y están cada vez más presentes en programas de entretenimiento y hasta en informativos. Estos son valores aceptados en nuestra mentalidad.

Al decir de Omar Calabrese «...Toda la cultura de una época se expresa, en mayor o menor cantidad y de un modo más o menos profundo, en la obra de cualquiera. Precisamente evitando jerarquías y marginaciones entre textos es posible descubrir el retorno periódico de algunos rasgos que distinguen nuestra mentalidad de la de otros períodos...» ${ }^{17}$

De allí, a considerar como lógico y natural que se den estas preferencias en los receptores, hay un paso.

Sin embargo, este principio de explicación es limitado. Porque los valores imperantes en una mentalidad no son legados divinos sino construcciones que emergen de las interacciones de los individuos entre sí y con su entorno; que se materializan en un determinado momento histórico - contextual y se expresan en sus obras.

Asimismo, se sabe que la recepción es producto de la interacción social (tanto en lo verbal como en lo extraverbal) entre locutor, auditor y aquello de lo que se habla ${ }^{18}$. Es un proceso complejo, que además de las competencias contextuales, ideológicas y lingüísticas de locutor y auditor, tiene que ver con un horizonte de expectativas relacionados con gustos personales y factores sicológicos de ambos. Estas competencias antes mencionadas son constructos que surgen de un complejo entramado de interacciones socio - culturales.

En estas últimas décadas, respecto a las interacciones sociales, el intercambio de roles entre los sexos y sus modificaciones constantes han transformado las concepciones de vida de los sujetos. Del mismo modo se ha modificado el concepto y práctica del goce de estos sujetos. Por lo tanto, no sería extraño que

17 Calabrese, Omar; «La era neobarroca» Ed. Cátedra, 1989, pág.12

18 La dimensión social del discurso queda clara en Todorov, cuando citando a Bajtin dice: «... La materia lingüística no constituye mas que una parte del enunciado; existe una parte no verbal que corresponde al contexto de la enunciación... El contexto extraverbal del enunciado se compone de tres aspectos: 1. El horizonte espacial común a los locutores (compuesto de elementos espacio-temporales, semánticos y evaluativos); 2. El conocimiento y la comprensión de la situación común a ambos; 3. La evaluación común de la situación... Cada enunciado cotidiano es como una palabra clave que conocen solamente aquellos que pertenecen al mismo horizonte social...» Todorov. : Mikhail Bakhtine Le Principe Dialogique Ed. Seuil, Paris, Francia. (1981: 78) 
estas transformaciones lleven a un acercamiento de ambos sexos en las preferencias del goce y por lo tanto de consumo y recepción de los productos culturales.

Otro factor a considerar es el denominado 'consumo involuntario'. Se sabe que desde muy pequeños los niños y niñas son instalados por igual frente al televisor y ven los programas que eligen sus padres, hermanos/as o niñeras. De esta forma, la TV, además de convertirse en un agente socializador cada vez mas importante, se transforma en constructora de las matrices de recepción que van definiendo el gusto y la preferencia que luego se plasma individualmente en el momento de la elección de programas ${ }^{19}$.

La cuestión no es sencilla. Por el momento hay mas preguntas que respuestas para este fenómeno de homogeinización de preferencias. ¿Seguirán homogeneizandóse las preferencias en función de estos géneros y valores alcanzando a los jóvenes de menor edad?. ¿Se consolidará la fragmentación de la programación en función de estos géneros?. ¿Esta homogeinización se expandirá hacia otros grupos etarios?

No obstante, éstos son los productos culturales que se renuevan permanentemente en canales como Sony, Warners o Fox: comedias ligeras, deportes y programas de acción ocupan lugares centrales. Ésta es la propuesta de programación más difundida por el cable que incluso se traslada a la programación abierta...

Como dice Fredric Jameson, existe una dominante cultural, que se materializa en un sistema económico internacional: el neoliberalismo salvaje. Acordes a esa dominante cultural son los productos y bienes simbólicos circulantes.

\section{Bibliografía:}

- Bell, Daniel ( 1990); Las contradicciones culturales del capitalismo. México.Grijalbo. 1990.

- Bell, Daniel; «El eclipse de la distancia» en La Mirada Oblicua. Estudios Culturales y Democracia; Delfino, Silvia, Ed. La Marca, Buenos Aires, 1993.

- Delfino, Silvia (1993), Estudios Culturales y Democracia; Ed. La Marca, Buenos Aires.

- Emanuelli y otros (1990): Informe Final Subsidio CONICOR año 1990, La recepción Juvenil de la TV, mimeo.

19 En este sentido, es notable como los primeros recuerdos de los adolescentes como receptores televisivos, aunque no son precisos, en general los sitúa con sus hermanos frente al televisor y en la mesa almorzando o merendando. 
- Emanuelli y otros (1997): Informe Final de Investigación Programa Incentivos año 1997, Proyecto 05/D100. La recepción de medios masivos de comunicación y nuevas tecnologías en Córdoba, mimeo. Centro de Investigaciones Jurídicas y Sociales. Universidad Nacional de Córdoba. Córdoba, Rep. Argentina.

- Ford, Aníbal (1987): «Aproximaciones al tema de federalismo y comunicación» en Landi, O. Medios transformación cultural y política. Buenos Aires, Legasa.

- Gándara, Santiago y otros (1997): Vidas imaginarias. Los jóvenes en la tele. Ed. Biblos, Buenos Aires, Argentina.

- Hall, Stuart; «La hegemonía audiovisual» en La Mirada Oblicua. Estudios Culturales y Democracia; Delfino, Silvia, Ed. La Marca, Buenos Aires, 1993.

- Hall, Stuart; «Nuevos Tiempos» en La Mirada Oblicua. Estudios Culturales y Democracia; Delfino, Silvia, Ed. La Marca, Buenos Aires, 1993.

- Jameson, Frederick (1991); Ensayos sobre el posmodernismo Ed. Imago Mundi, Buenos Aires, 1991.

- Jameson, Frederick; El posmodernismo o la lógica cultural del capitalismo avanzado, Ed. Paidós, Buenos Aires, 1992.

- Lipovestsky, Gilles (1996); La era del vacío. Ensayos sobre el individualismo contemporáneo, Ed. Anagrama, Barcelona,

- Lipovetsky, Gilles (1994); El crepúsculo del deber. La ética indolora de los nuevos tiempos democráticos. Ed. Anagrama. Barcelona.

- Lipovetsky, Gilles ( 1990); El imperio de lo efímero. Ed. Anagrama. Barcelona.

- Mata, María Cristina; Públicos y consumos culturales en Córdoba Proyecto de Investigación n ${ }^{\circ} 258$ Area de Estudios Sociales, Centro de Estudios Avanzados, Universidad Nacional de Córdoba, mimeo, 1995, Córdoba, Rep. Argentina.

- Sarlo, Beatriz (1994): Escenas de la vida Posmoderna: Intelectuales, arte y videocultura en Argentina. Ed. Ariel, Buenos Aires.

- Schmucler, Héctor y Terrero, Patricia (1996): Innovaciones tecnológicas y transformación de la televisión en Argentina, en Voces y Culturas $N^{\circ}$ 9, 1er. Semestre, Barcelona, España.

- Todorov.: Mikhail Bakhtine (1981): Le Principe Dialogique Ed. Seuil, Paris, Francia 